\title{
Calculation on Energy Saving Potential of a New Dry-type Air-conditioning System
}

\author{
Xiaowei Hu, Yufeng Zhang \\ School of Environmental Science and \\ Engineering, \\ Tianjin University \\ Tianjin 300072, China \\ E-mail: hu_xw2005@126.com
}

\author{
Lili Wei \\ School of Architecture and Civil \\ Engineering, \\ Ningbo University of technology \\ Ningbo 315016, China \\ E-mail: weilili990503@163.com
}

\author{
Xinhui $\mathrm{Wu}$ \\ Mechanical Engineering School, \\ Tianjin University of Commerce, \\ Tianjin 300134, China \\ E-mail:991290996@qq.com
}

\begin{abstract}
Temperature and humidity independent control can be made by a new dry-type air-conditioning system, the combination of silica gel rotor and heat pump. Heat pump cycle can simultaneously cool the process air and heat the regeneration air, so it can cancel each other out in the cold and heat energy consumption within the system. This novel form of system not only solves the regeneration energy issues fundamentally but also avoids energy waste by reheating in conventional cooling dehumidification air-conditioning system. Based on the establishment of the component model, MATLAB program has been compiled to simulate the combined system running at nominal operating conditions and calculate the performance parameters and energy efficiency. Comparison of the energy efficiency was made of this dry-type airconditioning system with ones of other regeneration desiccant wheel air conditioning system and conventional cooling dehumidification air-conditioning system, the results of which show that the new dry-type system provided regeneration energy, overcomes the restriction from climate, region and using conditions of other regeneration. Moreover, compared with conventional re-heat air-conditioning system, its energy saving is up to $35.1 \%$ and the energy efficiency is increased by $38.1 \%$.
\end{abstract}

Keywords- desiccant wheel air-conditioning system; silica gel wheel; high temperature heat pump; simulation calculation; energy saving potential;

\section{INTRODUCTION}

In both industrial and living environment, the relative humidity of the air plays a decisive role effect. The humidity control and regulation is needed in both comfort and industrial air-conditioning system. Cooling dehumidification and solid adsorbent dehumidification are mainly adopted in present air-conditioning system. In virtue of its good and stable performance, cooling dehumidification is applied widely. As in conventional vapor compression airconditioning system the minimum air will be cooled to dew point at $4^{\circ} \mathrm{C}[1]$, thus the ability of cooling dehumidifying will be limited by the dew point temperature, which also leads to Sick Building Syndrome [2-6] due to legionnella and other respiratory pathogens rapidly growing in the wet environment and energy waste of heat and cooling offset because of reheating.
Because of the separate cooling and dehumidification treatment, solid adsorbent dehumidification air conditioning system can realize temperature and humidity independent adjustment, in which the silica gel wheel has air purification effect [7]. Owing to the heat pump's collection and transfer of heat, the hot air after dehumidification is cooled down and regeneration air is heated simultaneously, the efficiency is offset of cold and heat within the system. Thus, the regeneration energy issues were solved fundamentally. Through establishing component model, the MATLAB program has been compiled to simulate the combined system at nominal operating conditions and calculate the performance parameters and energy efficiency. Through the comparison of the energy efficiency of this dry-type airconditioning system with ones of other regeneration desiccant wheel air conditioning system and conventional cooling dehumidification air-conditioning system, the energy-saving value and promotion potential were demonstrated.

\section{SYSTEM DESIGN AND WORKING PRINCIPLE}

The composition of the system is shown in figure 1. At the least cost of high-quality energy (mechanical, electrical energy etc.), the heat pump can provide regeneration air by extracting heat from hot air after silica gel absorption. The evaporator cools the hot air (about $40 \sim 50{ }^{\circ} \mathrm{C}$ ) after absorption down to apply air temperature, meanwhile the regeneration air is heated to $75-80{ }^{\circ} \mathrm{C}$ in the condenser. (experiments have verified that regeneration air temperature $75^{\circ} \mathrm{C}$ be better to desorption effect). The complementary of cold and heat lowers the energy consumption, solves the energy problem and simplifies the system components.

The workflow of this system includes dehumidification and regeneration. Mixture of return air and outdoor air is treated to state $\mathrm{A}$, then dehumidified by the silica gel to state $\mathrm{B}$, where the air temperature is significantly higher because of the steam's latent heat during absorption and thermal storage during regeneration. Then it is cooled to state $\mathrm{O}$ and achieves dehumidification. Regeneration means that the outdoor air at state W (can be mixed with some lowhumidity indoor return air) is heated by the condenser to required regeneration temperature, point $\mathrm{E}$, and then regenerate through the desiccant wheel. 


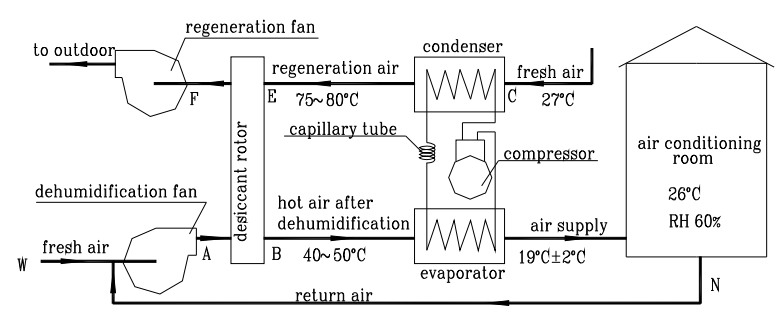

Fig.1 System flowchart of the solid adsorbent dehumidification air conditioning system

\section{MATHEMATICAL MODEL OF THE SYSTEM}

According to the system precision requirements, mathematical models of each components are established. With the output parameters of a component as the input parameters of the next component, the components models are combined organically to obtain the numerical computation of the system.

\section{A. Silica Gel Desiccant Wheel}

According to the literature [7], a more complete mathematical model of the one-dimensional heat and mass transfer is formed by partial differential equation of silica gel wheel adsorption and regeneration process with boundary conditions. By virtue of MATLAB matrix computation and storage functions, wheel's inlet and outlet air temperature and humidity parameters are calculated.

\section{B. Compressor}

The compressor completes inspiration, compression, exhaust in a working cycle. In order to simplify the model, the compressor is considered as a single node in the establishment of the steady-state lumped parameter model [8] [9]. The exhaust temperature of refrigerant can be calculated according to the steam compression process equation

$$
T_{d}=T_{\text {suc }}\left(\frac{p_{c}}{p_{e}}\right)^{\frac{k-1}{k}}
$$

Where $T_{d}, T_{\text {suc }}$ is exhaust and suction temperature respectively $(\mathrm{K}) ; P_{c}, P_{e}$ is for condensing pressure and evaporation pressure respectively $(\mathrm{Pa})$.

Compressor theoretical power

$$
N_{\text {th }}=\eta_{v} V_{\text {th }} p_{e} \frac{\mathrm{n}}{\mathrm{n}-1}\left[\left(\frac{p_{c}}{p_{e}}\right)^{\frac{k-1}{k}}-1\right]
$$

\section{Capillary tube}

To meet the overall system accuracy, adiabatic capillary tube can be divided into liquid phase and two-phase region. With the refrigerant flowing in adiabatic capillary tube, continuity equation, energy equation and momentum equation[9] can be constructed.

Continuity equation:

$$
m=\frac{\pi}{4} D^{2} G=c(\text { cons } \tan t)
$$

$$
h+\frac{1}{2} G^{2} v^{2}=c(\text { cons } \tan t)
$$

Momentum equation:

$$
-d p=G^{2} d v+\frac{1}{2} \frac{f}{D} v G^{2} d L
$$

Where $\mathrm{p}, v, \mathrm{~m}, \mathrm{G}$ are pressure, Specific volume, mass flow and mass flux respectively; D and L are inner diameter and length of capillary tube, $\mathrm{f}$ is friction factor.

\section{Condenser and Evaporator}

Evaporator and condenser are the main heat transfer components in heat pump system, the evaporator is divided into two-phase zone and overheated zone, and the condenser is divided into 3 zones including over-heat zone, two-phase zone and over-cold zone. A heat balance equations have been established between refrigerant inside tube and air outside tube as following

$$
Q_{a}=\gamma Q_{\mathrm{r}}
$$

Where $Q_{a} 、 Q_{\mathrm{r}}$ is the heat exchange of air side and refrigerant side heat respectively and $\gamma$ is the heat leakage coefficient value of 0.9 .

\section{E. Model Algorithm of the Combined System}

The main purpose of the systematic simulation is to calculate coupled output parameters, energy consumption and efficiency. The input parameters are specifications of desiccant wheel, compressor, evaporator, condenser and capillary tube, connection pipe structure parameters, air inlet parameters, refrigerant's superheat in condenser and refrigerant's super cooling in evaporator. The output parameters are outlet air temperature and humidity, required capillary tube length, condensing temperature, evaporating temperature, refrigerant flow, cooling capacity, heating capacity and energy efficiency ratio. The state parameters of air and refrigerant are calculated via their specific physical equation.

\section{COMPARED WITH PERFORMANCE AND ENERGY CONSUMPTION OF OTHER AIR CONDITIONING SYSTEMS}

The dry-type air-conditioning integrates the silica gel's air-cleaning and the heat pump's collection and highefficient heat transfer. The matching experiments of hightemperature heat pump in joint system were introduced in details in the literature [10]. The dry-type air-conditioning system (SYSTEM I) is being compared analytically with the other regeneration methods air-conditioning system (SYSTEM II) and conventional cooling dehumidification air-conditioning system (SYSTEM III).

Based on the nominal cooling condition, the air processes were shown in Fig.3. The process $\left.{ }_{N}^{W}\right\rangle_{N \rightarrow B \rightarrow O}$ is the dehumidification of SYSTEM I and the process $C \rightarrow E$ is heating for regeneration of desiccant wheel. The regeneration air is heated by heat pump's condenser in SYSTEM I and other heating methods in SYSTEM II. In

Energy equation: 
process $\left.\begin{array}{r}W \\ N\end{array}\right)_{A \rightarrow L \rightarrow O}$ in SYSTEM III, the mixture of return air and outdoor air at state A is cooled down to apparatus dew point $\mathrm{L}$ by vapor compression cycle for the purpose of dehumidification while is reheated to supply air temperature at point $\mathrm{O}$ in case of blowing cold air in the air-conditioned room. This is prevalent cool-reheat process. The energy consumption of the system mainly includes the compressor power, heating regeneration air and supply air reheat. Because the air volume in each system is similar and the impact on it is little, the fan energy consumption is ignored.

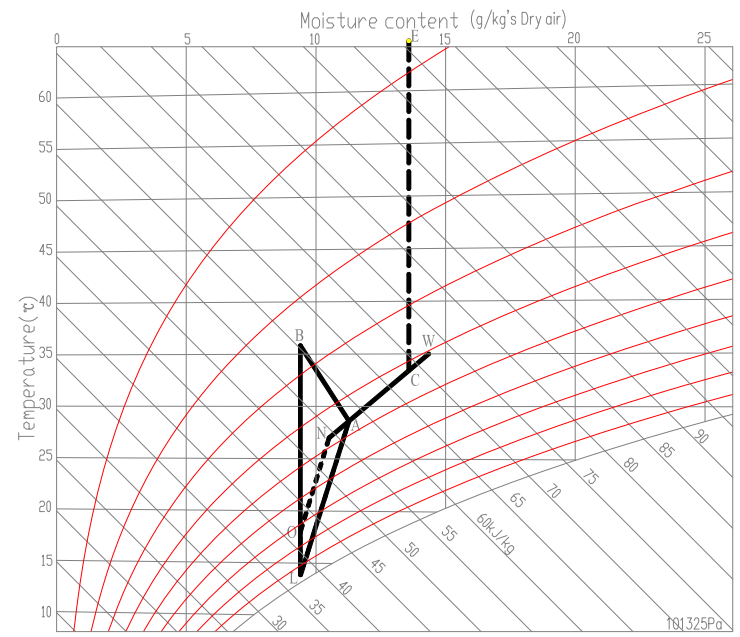

Fig.2 Enthalpy and humidity chart of processing point in compared systems

It is apparent from h-d diagram that the only difference of SYSTEM I and SYSTEM II is the methods of heating regeneration air from state $\mathrm{C}$ to state $\mathrm{E}$ in spite of fully consistent in cooling process after air dehumidification and heating process for regeneration air. In SYSTEM I, with evaporator cooling air and condenser heating regeneration air simultaneously, cooling and heating by itself within the system is implemented. In SYSTEM II, regeneration air can be heated by solar energy, geothermal energy, waste heat, electricity etc. No mater which is adopted, regeneration energy is needed. SYSTEM I is better than other desiccant wheel air conditioning system due to consumption of a little input power of the heat pump compressor without additional regeneration energy. Obviously, it is not energy saving by electricity heating in SYSTEM II, and it is limited by climate, region and local conditions in using solar energy, geothermal energy and waste heat. The qualitative comparative analysis is only done between SYSTEM I and SYSTEM II. Quantitative analysis will be carried out after cooling mode definite in SYSTEM II. SYSTEM I and SYSTEM III can be analyzed in the h-d diagram. In SYSTEM I, condenser heat heats the regeneration air from state $C$ up to $E$ while evaporator cools hot and dry air after desiccant wheel at state B down to supply air at state O. Cooling capacity is the enthalpy difference of state $\mathrm{B}$ and $\mathrm{O}$ multiplied by the amount of air supply. The total energy consumption of is the input power of compressor for the purpose of reaching regeneration temperature and air supply temperature. In refrigeration cycle of SYSTEM III, mixed air at state A by return air and outdoor fresh air is cooled down to apparatus dew point and then reheated to supply air temperature at state O. Cooling capacity is the enthalpy difference of state A and $\mathrm{O}$ multiplied by the amount of air supply. The total energy consumption of SYSTEM III includes the input power of compressor and the amount of reheating supply air. From the h-d diagram, the cooling capacity and operating conditions are different. SYSTEM I operates on higher evaporation temperature than SYSTEM III. Thus energy efficiency of SYSTEM I will be higher. To facilitate comparison, electric heating is adopted to heat regeneration air in SYSTEM III, with leakage heat loss being considered as 5\%. Vapor compression air-cooled or evaporative cooling electric compression cycle chiller is also adopted. According to

《The minimum allowable values of the energy efficiency and energy efficiency grades for water chillers》 GB195772004, vapor compression air-cooled or evaporative cooling electric compression cycle chiller takes priority of the most senior level energy-saving energy efficiency products whose coefficient of performance is 3.2. So, coefficient of performance 3.2 of the most energy-saving mature products is taken as the base of comparison in calculating input power of SYSTEM III. The SYSTEM I and SYSTEM III compared calculation results listed in table 1 . TABLE I. TABLE1. COMPARISON OF PERFORMANCE AND ENERGY
EFFICIENCY IN SYSTEM I AND SYSTEM III UNDER SUMMER AIR CONDITIONING NOMINAL CONDITIONS

\begin{tabular}{|c|c|c|c|}
\hline items & units & SYSTEM I & SYSTEM III \\
\hline$t_{L}$ & ${ }^{\circ} \mathrm{C}$ & -- & 13.9 \\
\hline$\varphi_{L}$ & $\%$ & - - & 95 \\
\hline$t_{E}$ & ${ }^{\circ} \mathrm{C}$ & 70 & - - \\
\hline$d_{E}$ & $g / k g$ & 13.29 & - - \\
\hline$Q$ & $k W$ & \multicolumn{2}{|c|}{13.09} \\
\hline$D$ & $\mathrm{~kg} / \mathrm{s}$ & \multicolumn{2}{|c|}{0.00113} \\
\hline$G_{O}$ & $m^{3} / h$ & \multicolumn{2}{|c|}{3719.9} \\
\hline$G_{C}$ & $m^{3} / h$ & 2636.7 & - - \\
\hline$Q_{\mathrm{COOL}}$ & $k W$ & 21.54 & 24.01 \\
\hline$Q_{\text {HEAT }}$ & $k W$ & 31.68 & - - \\
\hline$Q_{R E H}$ & $k W$ & - - & 14.35 \\
\hline$N_{\text {in }}$ & $k W$ & 14.68 & 22.61 \\
\hline $\mathrm{COP}_{\mathrm{C}}$ & $\square$ & 1.759 & 3.2 \\
\hline EER & 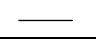 & 1.467 & 1.062 \\
\hline
\end{tabular}


Under summer nominal cooling conditions, outdoor air dry/wet bulb temperature is $35 / 24^{\circ} \mathrm{C}$, indoor air dry/wet bulb temperature is $27 / 19^{\circ} \mathrm{C}$; Air supply temperature difference is $8{ }^{\circ} \mathrm{C} ; t_{L}--$ dew point temperature; $\varphi_{L}$-- relative humidity at dew point temperature; $t_{E}$-- dry bulb temperature of regeneration air after heat pump condenser; $d_{E}$--moisture content of regeneration air after heat pump condenser; $Q$--cooling load of air conditioning room: $D$--wet load of air conditioning room: $G_{C}$--regeneration air volume; $G_{O}{ }^{--}$ supply air volume; $Q_{\text {cool }}$--cooling capacity; $Q_{\text {heat }}$-heating capacity; $Q_{r e h}$--reheating capacity; $N_{i n}$--input electric power; $C O P_{c}$--Compression refrigeration coefficient of performance; EER --energy efficiency ratio of air conditioning system

The data analysis shows that cooling capacity of SYSTEM I is lower than that of SYSTEM III because the vapor compression cooling unit in SYSTEM I undertakes only sensible heat load while it must undertake both sensible and latent heat load in SYSTEM III. The vapor compression cycle in SYSTEM I not only cools down supply air but also heats the regeneration air, thus although its COP is slightly lower than that of the currently mature energy-saving products, the EER of SYSTEM III is lower than that of SYSTEM I due to the electric consumption on reheating air from apparatus dew point to supply air temperature. This energy-saving effect will increase as the air conditioning latent heat load and required supply air temperature rises. That is why desiccant wheel air conditioning system of independent control of temperature, humidity takes advantage of other systems. Table 1 indicates that SYSTEM I saves energy $35.1 \%$ than SYSTEM III at nominal conditions of $8^{\circ} \mathrm{C}$ supply air difference. Thus the energy efficiency is increased by $38.1 \%$

\section{CONCLUSIONS}

The silica gel wheel and heat pump joint dry-type airconditioning system has a double effect of improving indoor air quality and reducing regeneration energy consumption. Compared with other types of desiccant wheel air conditioning system, its advantage is the heat pump's implement of cooling and heating within the system. The novel system overcomes the shortcoming of air conditioning system using other regeneration forms that is restricted by climate, region and use conditions. Energy consumption and energy saving potential should be compared according to heating methods for regeneration heating and dehumidification ways. The comprehensive utilization of energy should be compared. Apart from air purifying, the silica gel desiccant wheel air conditioning system has an advantage on independent temperature and humidity control compared with conventional cooling dehumidification and reheat air conditioning system. It is energy saving obviously and its energy saving potential will increase as air conditioning wet load.

\section{ACKNOWLEDGMENT}

The research was supported by the fund of Major State Basic Research Development Program of China (973 Program) under the contract No.2009CB219907.

\section{REFERENCES}

[1] Mazzei P, Minichielllo F, Palma D. "HVAC dehumidification systems for thermal comfort: a critical review," Applied Thermal Engineering, vol. 25(5-6), 2005, pp.677-707.

[2] P. Ole Fanger, "IAQ in the 21st century: search for excellence," Yu Xiaoming, journal of HV\&AC, vol. 30(3), 2000, pp.32-35.

[3] Wargocki P., "The effects of outdoor air supply rate in an office on perceived air quality, Sick Building Syndrome (SBS) symptoms and productivity, " Indoor Air, vol.10(4), 2000,pp.222-236

[4] Alm O., Clausen G., Fanger P.O., "Exposure-response relationships for emissions from used ventilation filters," Proc. of Healthy Buildings 2000, Helsinki, vol.2, 2000, pp.245-250.

[5] Schleibinger H., Ruden H., "Air filters from HVAC systems as possible source of volatile organic compounds (VOC) - laboratory and field assays," Atmospheric Environment, vol.33(28), 1999, pp.4571-4577.

[6] Higdon H.L., Graves J.E., Blackhurst D.W., Boone W.R., “Air quality within the incubator: will volatile organic compound (VOC) filters make a difference in vitro fertilization?" Fertility and Sterility, vol.80, 2003, pp.260.

[7] G.Zhang, Y.F.Zhang, L.Fang, "Theoretical study of simultaneous water and VOCs adsorption and desorption in a silica gel rotor," Indoor Air, vol. 18(1), 2008, pp.37-43.

[8] Y.Z.Wu, "Small refrigeration equipment design guidance," Beijing, 2001, 190-191

[9] G.L.Ding , C.L.Zhang, “ Simulation and optimization of refrigeration and air-conditioning device” , Beijing, 2001, 8

[10] Y.F.Zhang, X.W.Hu, Q.S.Miao, L.L.Wei, C.M.Chen, H.Hao, "Cycle Performance of heat pump in desiccant cooling system," CIESC Journal, vol.60, Sep, 2009, pp.2177-2182. 